\title{
Los patios de entrada a las tumbas tebanas en época de Hatshepsut-Tutmosis III y los patios de Djehuty (TT 11) y de Baki en Dra Abu el-Naga
}

J. M. GALÁN

El objetivo del presente artículo es describir y realizar un primer análisis de los patios de entrada a las tumbas de Djehuty (TT 11) y Baki, ubicadas al pie de la colina de Dra Abu el-Naga. Para ello, una prospección de los patios de comienzos de la dinastía XVIII ayudará a contextualizarlos y comprender mejor el valor de este reciente descubrimiento.

The courtyards of the Theban tombs in the reign of Hatshepsut-Thutmose III and the courtyards of Djehuty (TT 11) and Baki in Dra Abu el-Naga

The aim of the present article is to describe and assess the open courtyards of the tombs of Djehuty (TT 11) and Baki, located in the foothill of Dra Abu el-Naga. For this purpose, a survey of early $18^{h}$ Dynasty courtyards will help to contextualize them, and enable a better understanding of the relevance of this recent discovery.

KEY wORDs: Thebes, Hatshepsut, Thutmose III, courtyard, tomb

$\mathrm{L}$ os monumentos funerarios que se constru${ }_{y}$ yeron los miembros de la elite en la Tebas de la dinastía XVIII, en la primera mitad del siglo XV a. C., se localizan en la orilla oeste, en la falda de las colinas rocosas que se elevan a casi cuatro kilómetros del Nilo, justo hasta donde llegaban las aguas del río en el momento álgido de la inundación anual.

En líneas generales, éstos constan de dos partes $^{1}$. Por un lado se encuentra la tumba propiamente dicha: en la roca del suelo se excavaba un pozo vertical de las dimensiones de un ataúd rectangular, aproximadamente 1 x 2 m, y más o menos profundo, que acababa en una o más cámaras sepulcrales. Allí se alojaba el ataúd junto con el equipamiento funerario: algunos bienes de lujo, pero, sobre todo, objetos de la vida cotidiana, comida y guirnaldas de flores. Una vez depositado dentro el difunto y su ajuar, el pozo se bloqueaba con piedras y tierra, que debían evitar que nadie interrumpiera su descanso eterno. El acceso a esta parte, al sepulcro, estaba prohibido.

La otra parte que constituía el monumento funerario seguía un plano horizontal, se excavaba en la falda de la colina y penetraba dentro de la propia roca. Era una especie de cuevasantuario o speos en honor a la memoria del difunto. La planta recuerda, efectivamente, a la de un templo, con un pasillo central que conduce hasta una sala donde se encuentra la esta-

1. Una representación muy ilustrativa de la distinción entre las dos partes del monumento funerario se encuentra en el Libro de los Muertos de Nebqed (Museo del Louvre, AE/N 3068), de mediados de la dinastía XVIII; Naville, 1886: vol. I, pl. 4; Forman y Quirke, 1996: 122-23; Assmann, 2001: 130. Ver, Seyfried, 1987: 219-53, pl. 20-25; Polz, 1987 : 119-40; Kampp-Seyfried, 2003: 2-10; Galán, 2007c.

Fecha de recepción: 5 de octubre de 2006

Fecha de admisión: 28 de febrero de 2007 
tua del difunto, acompañado por su esposa y/o por uno o sus dos progenitores. No en vano, el difunto, al ser enterrado siguiendo los rituales pertinentes, se convertiría, supuestamente, en un noble espíritu, excelente y bien equipado, en el cielo junto a $\mathrm{Ra}$; en un poderoso en la tierra junto a Geb; y en un (santo) inocente (o justificado de voz) en el cementerio junto a Osiris ${ }^{2}$. Además, su $b a$ sería divinizado, como se le deseaba en las inscripciones ${ }^{3}$. Las paredes interiores, como las de cualquier otro templo o capilla, estaban profusamente decoradas, y el espacio quedaba abierto a las visitas que, también como en los templos, tendían a seguir un calendario religioso establecido ${ }^{4}$. El difunto deseaba recibir visitas en su casa de la necrópolis; visitas de familiares, allegados y de cualquier persona bien intencionada, para que pronunciaran su nombre y revivieran así su recuerdo, para que invocaran las ofrendas de alimentos y para que, leyendo las inscripciones y observando las escenas figurativas, conocieran los méritos que le hacían merecedor de una vida eterna en el Más Allá, junto a los demás "justos" y "venerados".

Esta segunda parte del monumento, la zona accesible, constaba a su vez de dos ámbitos. Uno cubierto, metido dentro de la colina, compuesto, generalmente, por varias salas. Cada una de ellas estaba, en principio, decorada o ambientada con inscripciones y escenas de temas concretos, como el banquete funerario en el que participa el propio difunto junto a sus familiares, la caza y pesca en los pantanos, la caza con arco y flechas en el desierto, la peregrinación a Abidos, el aprovisionamiento de ofrendas, etc ${ }^{5}$.

El otro ámbito era el área más pública, pues se encuentra al descubierto, al aire libre, a plena luz. Es el patio de entrada. Éste tenía su importancia, por un lado, por ser la parte más visible del monumento y la primera a la que se accedía; por otro lado, porque aquí se realizaban sobre la momia y el ataúd el conjunto de rituales que los antiguos egipcios agrupaban bajo el epígrafe "Apertura de la Boca", y que pretendían devolver al difunto su capacidad de acción y sus facultades sensoriales para poder vivir plenamente en el Más Allá ${ }^{6}$. En palabras de Jan Assmann:

El patio es el lugar de transición e iniciación, de purificación y consagración. Los rituales en el patio preparan al difunto para entrar en la tumba como un lugar sagrado en completa pureza. (...) La función de templo que posee la tumba requiere un patio. Un templo ha de estar precedido de un patio delimitado que sirva de zona intermedia entre la estancia divina y el mundo exterior, y que ofrezca un lugar para llevar a cabo los rituales al aire libre, como por ejemplo 'la erección de la momia delante de $\mathrm{Ra}^{ }{ }^{7}$.

Muy probablemente, el ritual de la Apertura de la Boca se desarrollaba en el patio de una forma abreviada, concentrándose en tres aspectos: la consagración de la momia con incienso y agua, el sacrificio de la pata y el corazón, y el vestir a la momia delante de Ra. Estos son los rituales que en las tumbas se representan teniendo lugar en el patio. Mi tesis es que precisamente para llevar a

2. Urk. IV 1525, 4-7.

3. Urk. IV 114, 3 ("que tu $b a$ (Paheri) sea divino junto a los espíritus"); Urk. IV 1218, 11 ("que tu ba (Amonemhat 'Imiseta') sea divino junto a los dioses").

4. Spalinger, 1996. Ver también Abdul-Qader Muhammed, 1966: 132-33; Bleeker, 1967: 131-40. Sobre la "Bella fiesta del Valle", Graefe, 1986: 187-89.

5. Abdul-Qader Muhammed, 1966; Engelmann-von Carnap, 1999.

6. Sobre algunos aspectos del ritual de la Apertura de la Boca, véase la comunicación de J. M. Serrano en este volumen.

7. Assmann, 2003a: 51. 
cabo estos rituales se introduce el patio delimitado dentro de la arquitectura de la tumba durante el Reino Nuevo ${ }^{8}$.

La descripción que hace Assmann de la tumba en época ramésida es válida, en su mayor parte, también para las de la dinastía XVIII. El patio de Djehuty y el extenso himno a AmónRa tallado en uno de los lados de la fachada demuestran que muchos aspectos de la "innovación" que Assmann adscribe a la dinastía XIX ya estaban presentes en época de HatshepsutTutmosis III ${ }^{9}$.

El patio de entrada al monumento funerario, al igual que los elementos arquitectónicos que pudieran coronar la fachada, como podían ser un friso de conos de arcilla, un nicho con una estatuilla del propietario en actitud orante o sosteniendo una pequeña estela con un himno solar, o una pequeña pirámide levantada mediante mampostería y adobes, al estar en el exterior, quedaban a merced de las inclemencias de la naturaleza y de la acción destructiva del hombre. Debido a su vulnerabilidad, han sufrido enormemente y todavía hoy siguen padeciendo, por lo que han perdido gran parte de sus características esenciales y ornamentales. Así, como cabría esperar, los primeros egiptólogos que excavaron e investigaron la necrópolis tebana, seducidos por las inscripciones y escenas que decoraban las paredes interiores, ignoraron en gran medida los patios de entrada. Sólo un número muy reducido han sido debidamente excavados y documentados, por lo que se conocen pocos detalles de esta primera e importante área del monumento funerario.
Así lo reconocía el propio Norman de Garis Davies, en la publicación de la tumba de Puiemra (TT 39), segundo profeta de Amón bajo Hatshepsut-Tutmosis III, ubicada en el-Asasif y cuyo patio de entrada fue excavado en 1915-1916:

Muy poca atención se ha prestado al exterior de las tumbas tebanas, en parte porque las investigaciones pertinentes conllevan un gasto considerable para escasa recompensa, en parte porque se requiere mucho esfuerzo y conocimientos para recuperar algún rastro de los elementos originales de entre la maraña de enterramientos posteriores ${ }^{10}$.

Se encuentran casos dramáticos como el de la tumba del mayordomo y heraldo del rey bajo Hatshepsut y Tutmosis III, Djehuty (TT 110), enterrado en Sheikh Abd el-Qurna. Davies describe la situación de la siguiente manera:

En la actualidad [es decir, poco antes de 1930] se entra por detrás de la sala más profunda, por donde se ha roto la delgada pared de roca que la separa de la Tumba 42. Su puerta original, orientada al este, debe encontrarse en un patio independiente y hundido, al este del de la Tumba 42 y al sur del de la Tumba 112. Pero en la actualidad debe estar enterrado muy profundo $y$, como las jambas de la entrada no parecen estar decoradas, poco o nada puede ganarse de su excavación ${ }^{11}$.

Hoy en día la situación sigue siendo prácticamente la misma que entonces: no conocemos nada sobre el patio de la TT 110.

El caso de Montuherkhepeshef (TT 20), portador del abanico bajo Tutmosis III, es también significativo. Su tumba, situada en Dra Abu el-Naga,

8. Assmann, 2003b: 60.

9. En este sentido, véase el propio Assmann, 1987: 47-55.

10. Davies, 1922: II, 51.

11. Davies, 1932: 279. Davies informa en la n. 1 que Weigall despeja su acceso en el otoño de 1909. Ver plano en pl. 38; Kampp, 1996: I, 390-91. 
a escasos $50 \mathrm{~m}$ al norte de "nuestro" Djehuty (TT 11), fue descubierta por Gaston Maspero en 1882, quien entró en ella a través de la vecina tumba de Nebamón (TT 24). Veintiocho años después, en 1910, Arthur Weigall excavó su interior con el propósito de bloquear los accesos subterráneos y evitar así que continuara el expolio de fragmentos de las paredes, talladas en relieve con gran lujo de detalles. Al final de ese mismo año, Davies se dedicó a copiar las escenas, es decir, lo que quedaba de ellas, para su publicación. Él mismo cuenta lo siguiente:

Habiendo obtenido una pequeña subvención de la Egypt Exploration Fund, pude excavar por primera vez la sala transversal y la entrada, y obtuve la recompensa de hallar cientos de fragmentos, conocidos y desconocidos, y algunos objetos interesantes del equipamiento funerario. En la siguiente campaña el pozo de enterramiento fue vaciado y se hallaron así algunos fragmentos más. Una excavación más extensa de los alrededores probablemente incrementaría el número $\mathrm{y}$, puesto que algunos signos jeroglíficos seguidos podrían ser enormemente esclarecedores para comprender las escenas, sería deseable que pudiera llevarse a cabo algún día ${ }^{12}$.

Sin embargo, nunca se llegaron a excavar los alrededores de la tumba de Montuherkhepeshef.

En los últimos años esta actitud ha tratado de corregirse y los arqueólogos que han trabajado y trabajan en la necrópolis de la antigua Tebas han ido concediendo cada vez mayor importancia a las partes exteriores del monumento objeto de su investigación. El exponente más claro de este nuevo enfoque es la tesis doctoral de Friederike Kampp, Die Thebanische Nekropole: zum Wandel des Grabgedankens von der XVIII. bis zur XX. Dynastie, Mainz 1996 ${ }^{13}$, que documenta y describe en la medida de lo posible los patios de entrada y el exterior de cada una de las tumbas, así como su evolución arquitectónica.

Los patios de entrada a los monumentos funerarios terminan en la fachada de la parte excavada en la colina, que está tallada en la roca y en muchos casos recrecida con bloques de piedra. Los laterales del patio generalmente se delimitan mediante muros tallados en la roca, cuya parte superior suele seguir el perfil descendente de la falda de la colina hasta alcanzar el suelo. Los patios pueden estar tallados al nivel de la roca madre ( gebel) de la zona, o pueden estar rehundidos en la roca por debajo del nivel del suelo natural.

En el caso de los patios rehundidos, se pueden conocer con facilidad las dimensiones y suelen conservarse mejor los muros laterales y la fachada. Tienden a ser de tamaño reducido y de planta casi cuadrangular, llegando en algunos casos a ser más anchos que largos. La anchura generalmente coincide en gran medida con la longitud de la sala transversal en el interior. Al patio se accede descendiendo por unos escalones o una rampa. Un ejemplo temprano de este tipo se encuentra en el extremo norte de Dra Abu el-Naga, en el monumento funerario de Baki (TT 18), encargado de pesar el oro y la plata durante el reinado de Tutmosis III, o incluso en una época más temprana. Está ligeramente hundido, y se accede a él por medio de una pequeña escalinata. Sus dimensiones son reducidas, $5 \mathrm{~m}$ de largo por 4,5 de ancho. Henri Gauthier inspeccionó la tumba en 1906 y escribió lo siguiente:

Según los árabes de alrededor, había sido excavada unos años antes por M. Percy E. Newberry, al igual que muchas otras tumbas

12. Davies, 1913: 1-2. Ver plano de la tumba en pl. 15; Kampp, 1996: I, 201-03.

13. Un resumen en inglés de algunos aspectos de su tesis doctoral puede encontrarse en Kampp-Seyfried, 2003. 


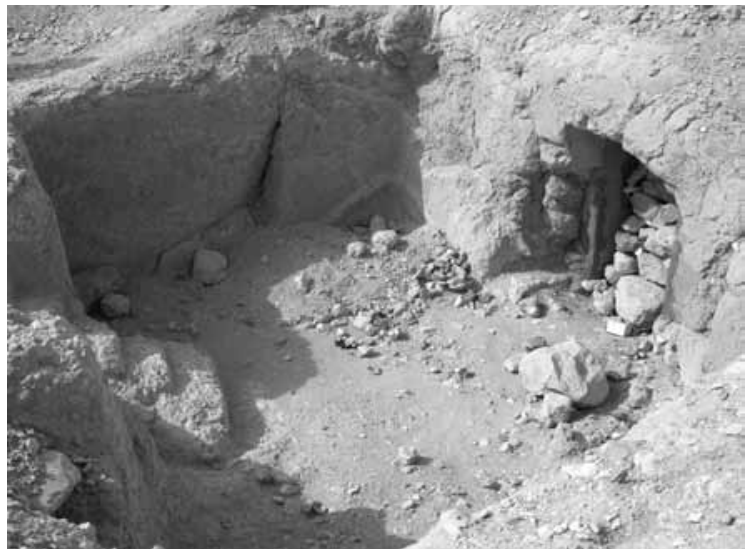

Figura 1. Patio de la tumba de Baki, "encargado de pesar el oro y la plata”, TT 18

de la zona de Dra Abu el-Naga donde nosotros habíamos trabajado. El arqueólogo inglés no había encontrado ningún objeto, pues había sido vaciada antes de la llegada de los egiptólogos. No habiendo M. Newberry publicado la tumba, que yo sepa, he creído oportuno copiar lo que queda antes de que se destruya en su totalidad ${ }^{14}$.

Los escalones de entrada también se conservan, por ejemplo, en el monumento de un oficial de la segunda mitad del reinado de Tutmosis III, Paheqamen, también llamado Benia (TT 343), en Sheik Abd el-Qurna, excavado por Robert Mond en $1926^{15}$. La pequeña escalinata por la que se desciende al patio está flanqueada por unos pequeños muretes construidos con adobes, que puede considerarse que hacen la función de pilonos de entrada. Las dimensiones del patio son 10,50 $\mathrm{m}$ de largo por 8,70 $\mathrm{m}$ de ancho.

Los patios tallados al nivel del suelo se conservan en peor estado y, por tanto, se conocen peor sus características, sobre todo los detalles de su entrada. En la mayoría de los casos no sabemos cómo eran, ni cuánto medían de largo. Las tumbas ubicadas a media altura en la colina tenían, lógicamente, menos posibilidades de poseer un patio de entrada alargado, por lo que en algunos casos, como en el de Senenmut (TT 71), la explanada delante de la entrada se alarga de forma artificial mediante una terraza de lascas de piedra caliza ${ }^{16}$.

El interior de la tumba del visir de Tutmosis III, Rekhmira (TT 100), se excavó en 1889 y se colocó entonces una puerta con barrotes de hierro para proteger sus maravillosas pinturas. El patio de entrada fue excavado por Percy E. Newberry once años después, en 1900. En la publicación que posteriormente hace Davies, señala en las primeras páginas:

El patio esta densamente cubierto de basura por el lado exterior, por lo que sus límites no se pueden conocer; pero las tumbas de la época raramente poseen una demarcación del patio por medio de un muro exterior o pilono (...) En 1935 despejé el patio hasta una distancia de 11 metros de la fachada. El Servicio de Antigüedades ha de despejar un área más extensa, aunque sólo sea para mejorar la actual y poco aparente entrada a las tumbas ${ }^{17}$.

Pero nunca se llegó a hacer. El patio de Rekhmira es excepcionalmente grande, en consonancia con las dimensiones de la parte cubierta del monumento funerario. Mide $19 \mathrm{~m}$ de ancho y de largo más de $13 \mathrm{~m}$. Davies asumió que no tenía una entrada marcada, pero, ¿cuántos patios habían sido excavados en su integridad para poder afirmar esto?

14. Gauthier, 1906: 163-64. La tumba sería luego visitada por Petrie, quien publica sus anotaciones en Petrie, 1909: 11; Kampp, 1996: I, 199-200.

15. Mond y Emery, 1927: 28-29, pl. 19, 33; Guksch, 1978: 11-12, pl. 1; Kampp, 1996: II, 582-83.

16. Dorman, 1991: 24, pl. 1, 3.

17. Davies, 1943: I, 6 y n. 14. Una fotografía del patio puede encontrarse en la portadilla del vol. I, y un plano en vol. II, pl. 6; ver también, Kampp, 1996: I, 370-73. 
Los patios tallados a nivel del suelo, al igual que los rehundidos en la roca, tienden a tener una anchura similar a la longitud de la sala transversal. Del mismo modo, parece que también tienden a ser de planta cuadrangular, y muchas veces más anchos que largos; claro que hay que tener en cuenta que la entrada a muchos de ellos no ha sido excavada. Rekhmira no es en este sentido una excepción. El patio de la tumba de Menkheperraseneb (TT 86), primer profeta de Amón bajo Tutmosis III, fue excavado por Mond en 1903, y Davies lo describe treinta años después de la siguiente manera:

El patio está tallado de forma muy tosca, habiéndose despejado un camino llano hacia la puerta entre la roca parcialmente extraída. El borde de la ladera está todavía enterrado en basura $^{18}$.

La anchura de los patios tallados a nivel del suelo oscila entre 7 y $14 \mathrm{~m}$, siendo excepcionalmente anchos los de Puiemra (TT 39) con 18 m, Rekhmira (TT 100) con 19 m, Ineni (TT 81) con $20 \mathrm{~m}$, Useramon (TT 131) también con $20 \mathrm{~m}$, y Senenmut (TT 71) con $24 \mathrm{~m}$. Con respecto a la anchura de estos patios, hay que tener en cuenta que en algunos casos se reutilizan tumbas del Reino Medio, denominadas "saff", cuya fachada con grandes pilares pretendía ser espectacular ${ }^{19}$. Hasta donde se puede saber, la longitud más común de los patios coincide aproximadamente con la anchura, oscilando también entre los $5 \mathrm{y}$ $11 \mathrm{~m}$. Excepcionalmente largos son los patios de Hapuseneb (TT 67) con 14 m, Puiemra (TT 39) con $18 \mathrm{~m}$, Menkheperraseneb (TT 79) con $18 \mathrm{~m}$, y Rekhmira (TT 100) con 19 m. Estas medidas son aproximadas y es muy probable que midieran unos metros más.
El "Proyecto Djehuty", en consonancia con la tendencia actual de excavar y estudiar el monumento funerario de forma integral, incluyendo el exterior, ha dedicado especial atención, durante las cinco primeras campañas anuales de trabajo de campo (2002-06), a la excavación de los patios de entrada ${ }^{20}$.

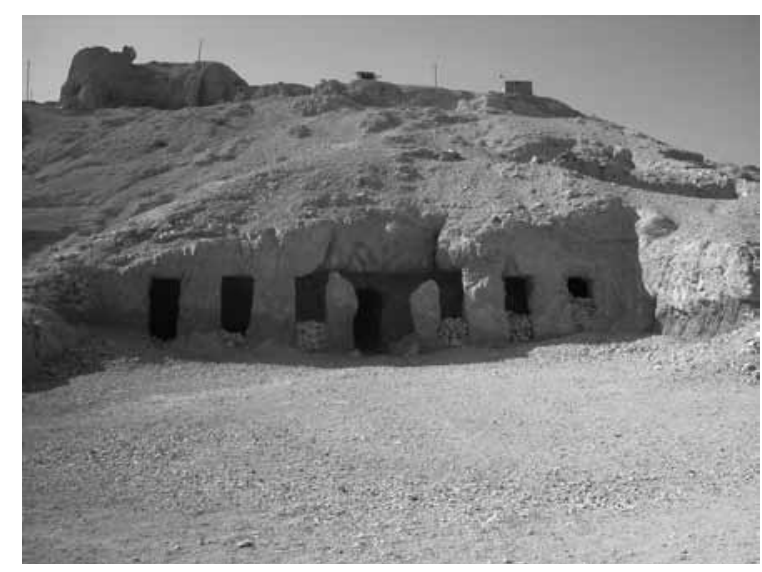

Figura 2. Entrada a la tumba de Hapuseneb, TT 67

En la cuarta campaña, en febrero de 2005, para poder seguir descendiendo hacia el suelo del patio de la tumba de Hery (TT 12) sin que se nos viniera abajo el corte lateral, ampliamos el área de excavación cuatro metros hacia el noreste. En este proceso, descubrimos el patio de entrada a una tumba contigua por el noreste, pero ubicada unos dos metros más arriba de la falda de la colina (por esta razón salió a la luz antes que el de Hery). Las dos tumbas se conectan entre sí por dentro, y fue a través de esta nueva cómo Champollion y Rosellini tuvieron acceso al pasillo de Hery en 1829 (la entrada original estaba entonces totalmente enterrada). El suelo de la parte interior del monumento está cubierto por

18. Davies y Davies, 1933: 1. Ver plano en pl. 2; Kampp, 1996: I, 338-40.

19. Este puede ser el caso, entre otros, de Ineni (TT 81) y de Hapuseneb (TT 63), con 14 m. Algunos miembros de la siguiente generación de altos oficiales imita la fachada de sus predecesores, como es el caso de una de las tumbas de Senenmut (TT 71). Ver Dziobek, 1987: 78-79.

20. Sobre el "Proyecto Djehuty", véanse en la bibliografía los artículos de Galán. 
más de un metro de escombro. Las paredes y el techo están muy desfigurados y, por lo que sabemos hasta la fecha, sólo se conservan restos de un friso-heker pintado sobre estuco a la entrada, junto a un estrecho nicho que alojaba una estatua del propietario tallada en la propia roca de la colina. El techo de la entrada se desplomó en algún momento, dándole al espacio interior una apariencia todavía más de "caverna", como así lo describió Champollion en su cuaderno de campo ${ }^{21}$.

La calidad de la piedra caliza a esta altura de la colina, por encima de las tumbas de Djehuty y de Hery, es pobre, volviéndose poco compacta, margosa y exfoliable. Por este motivo, la fachada se les destruyó a los propios constructores del monumento y tuvieron que recomponerla mediante mampostería. Para compensar el desperfecto causado, usaron bloques de piedra caliza, y arenisca para las jambas de la entrada, una piedra más dura y apreciada. Varios fragmentos de las jambas salieron a la luz en la excavación del patio, y uno que todavía se encontraba colocado en su sitio nos confirmó la ubicación original de los que estaban caídos sobre el suelo. Las jambas, de 23/24 cm

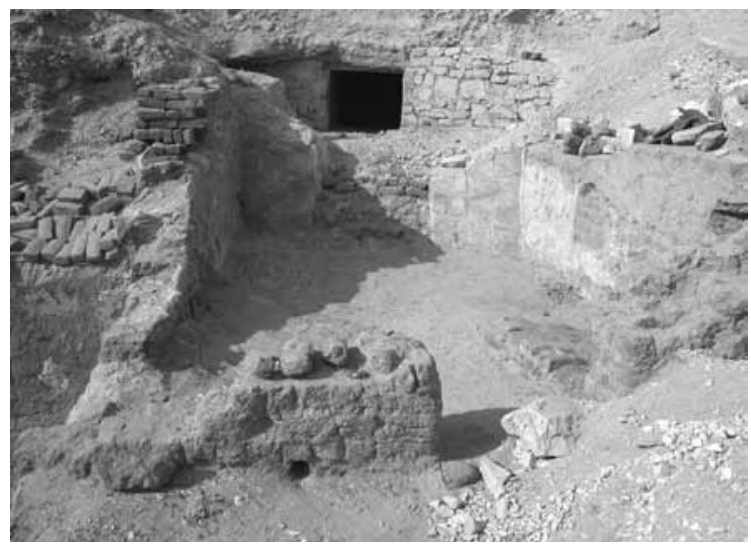

Figura 3. Patio de la tumba de Baki, "supervisor del ganado de Amón”, visto desde el exterior de anchura cada una, están inscritas con un texto en dos columnas, y algunos de los signos todavía conservan restos de color amarillo. La inscripción vertical solicita la invocación de ofrendas para el propietario del monumento, terminando con su nombre y el cargo principal que desempeñó en vida: “...el supervisor del ganado de Amón, Baki”. La epigrafía y otros elementos de la inscripción señalan que muy probablemente Baki debió de vivir a comienzos de la dinastía XVIII y morir bajo el reinado de Tutmosis III ${ }^{22}$.

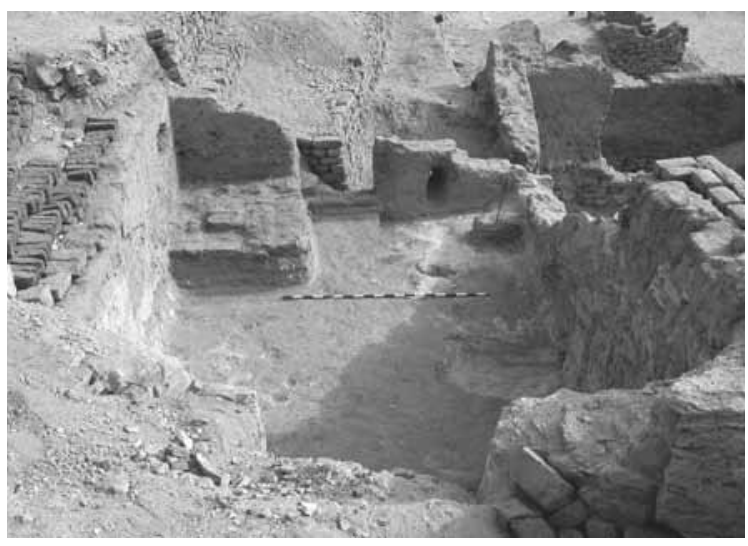

Figura 4. Patio de la tumba de Baki, visto desde encima de la fachada

El patio posee unas dimensiones algo reducidas: 4,52/4,45 $\mathrm{m}$ de largo por 3,75 $\mathrm{m}$ de ancho en la fachada y $3,40 \mathrm{~m}$ a la entrada del patio. Una vez colocadas las jambas en su sitio, el vano de aceso a la parte interior del monumento funerario tendría la anchura habitual: $0,90 \mathrm{~m}$. Los muros laterales tienen en su estado actual 1,34 y $1,18 \mathrm{~m}$ de altura, y por la parte interior estaban recubiertos de un enlucido. Sin duda, uno de los aspectos más interesantes es que conserva en bastante buen estado la entrada al patio. La entrada, en el lado sur, se define mediante la elevación de dos muros de adobe a los lados, de

21. Champollion, 1973: I, 543-44.

22. Serrano Delgado, 2005: 85-98. 
$0,45 \mathrm{~m}$ de grosor y que en la actualidad tienen 0,67 y $1,59 \mathrm{~m}$ de altura. Los muros de adobe dejan una apertura en el centro de $0,90 \mathrm{~m}$, justo la anchura para dejar pasar un ataúd. En el umbral se conservan un par de escalones de adobe que hay que subir para entrar al patio.

La tumba de Djehuty había sido excavada por el Marqués de Northampton, Wilhelm Spiegelberg y Newberry a comienzos del año $1899^{23}$. La campaña duró unos cuatro meses, cubrió prácticamente la colina entera de Dra Abu el-Naga y transcurrió a un ritmo acelerado. No prestaron apenas atención al exterior de los monumentos funerarios, a pesar de que la fachada y parte de los muros laterales del patio de Djehuty habían sido tallados con extensas inscripciones (una estela biográfica, otra con un himno a Amón-Ra y dos plegarias escritas con signos criptográficos) y con escenas de banquete y ofrendas funerarias, además de incluir dos estatuas del propietario en las esquinas ${ }^{24}$. Esto es una circunstancia excepcional, pues en la mayoría de los casos las fachadas no se decoraban, y solo las jambas y el dintel de la puerta eran inscritos con un texto de invocación de ofrendas en nombre del propietario (como en la vecina tumba de Baki que acabamos de describir). En el mejor de los casos se tallaba, además, una imitación de una "fachada de palacio", como en la tumba de Useramón (TT 131) ${ }^{25}$ y de Puiemra (TT 39). Este último es, tal vez, el único oficial de la época junto con Djehuty que decora pro- biográficas como himnos religiosos ${ }^{26}$. El esmero con el que se había tallado la fachada de la tumba de Djehuty anunciaba que su propietario o el arquitecto había concedido una gran importancia al área exterior del monumento funerario.

Poco a poco se fue descubriendo que efectivamente era así, pues el patio de Djehuty poseía unas dimensiones fuera de lo común. En la quinta campaña, en febrero de 2006, sacamos a la luz por fin la entrada, convirtiéndose así en uno de los pocos patios de comienzos de la dinastía XVIII excavados y documentados. Además, el patio de Djehuty mostraba unas características muy particulares.

La fachada mide unos $3 \mathrm{~m}$ de altura. Cuando al año siguiente excavamos por encima, descubrimos que se había construido un muro de mampostería para recrecer la fachada $2 \mathrm{~m}$ más. La superestructura mide $9 \mathrm{~m}$ de longitud, alcanzando el exterior de los muros laterales del patio, y su anchura oscila en torno a 1,85 m. Parece que la parte de arriba acaba en un plano horizontal, liso. El interior estaba compuesto de tierra, piedras y adobes, mientras que la cara externa estaba muy bien acabada con bloques de piedra caliza muy bien tallados y unidos por un mortero muy fino. La parte de atrás de la estructura se conserva en relativo buen estado, pero la parte de delante se ha perdido completamente. No podemos conocer con exactitud cómo estaba coronada la entrada a la parte interna del monumento, pero al menos sí sabemos, gracias a los

23. The Marquis of Northampton, Spiegelberg y Newberry, 1908; Spiegelberg, 1899 (dos cuadernos manuscritos guardados hoy en el archivo del Griffith Institute, Oxford).

24. Sobre el carácter excepcional de la fachada de la TT 11, al incluir estatuas del difunto y estelas, ver Kampp, 1996: I, 74-77.

25. Sobre las inscripciones grabadas en la "fachada de palacio" (formada por una sucesión de estelas de "falsa puerta"), ver Dziobek, 1994: 51-60, pl. 39-40, 44, 46. Otras tumbas más modestas, como por ejemplo la de Nebamón (TT 24), en Dra Abu el-Naga, a cincuenta metros al norte de la tumba de Djehuty (TT 11), talla junto a la puerta de entrada una estela de "falsa puerta", con un texto de invocación de ofrendas; ver Kampp, 1996: I, 209-10. Otras tumbas de interés en este sentido son: TT 109, 164 y 224. En época ramésida será ya común tallar una o más estelas en la fachada; ver Hermann, 1940: 25.

26. Además de inscripciones en la fachada, parece ser que había escenas talladas en los muretes que se levantaron entre las columnas que precedían a la fachada; Davies, 1922: I, 4-7, 39-42, pl. 3; II, 43-47, 51-56, pl. 66-72, 75. 
hallazgos de la excavación del patio, que tendría más de doscientos conos funerarios ${ }^{27}$ dispuestos en hileras, empotrados en la superestructura.

Si bien la anchura del patio de Djehuty entra dentro de los parámetros normales, pues la fachada mide 7,60 m de lado a lado, su longitud es realmente excepcional: $34 \mathrm{~m}$ de largo (téngase en cuenta que el de Rekhmira, el más largo de la época hasta donde sabíamos ayer, mide $19 \mathrm{~m}$; es decir que el de Djehuty le supera en $15 \mathrm{~m}$ ).

Los muros laterales del patio están tallados en la roca, que mantiene el perfil descendente de la ladera de la colina, tocando el suelo a $12 \mathrm{~m}$ de la fachada. Los muros mantenían la altura inicial

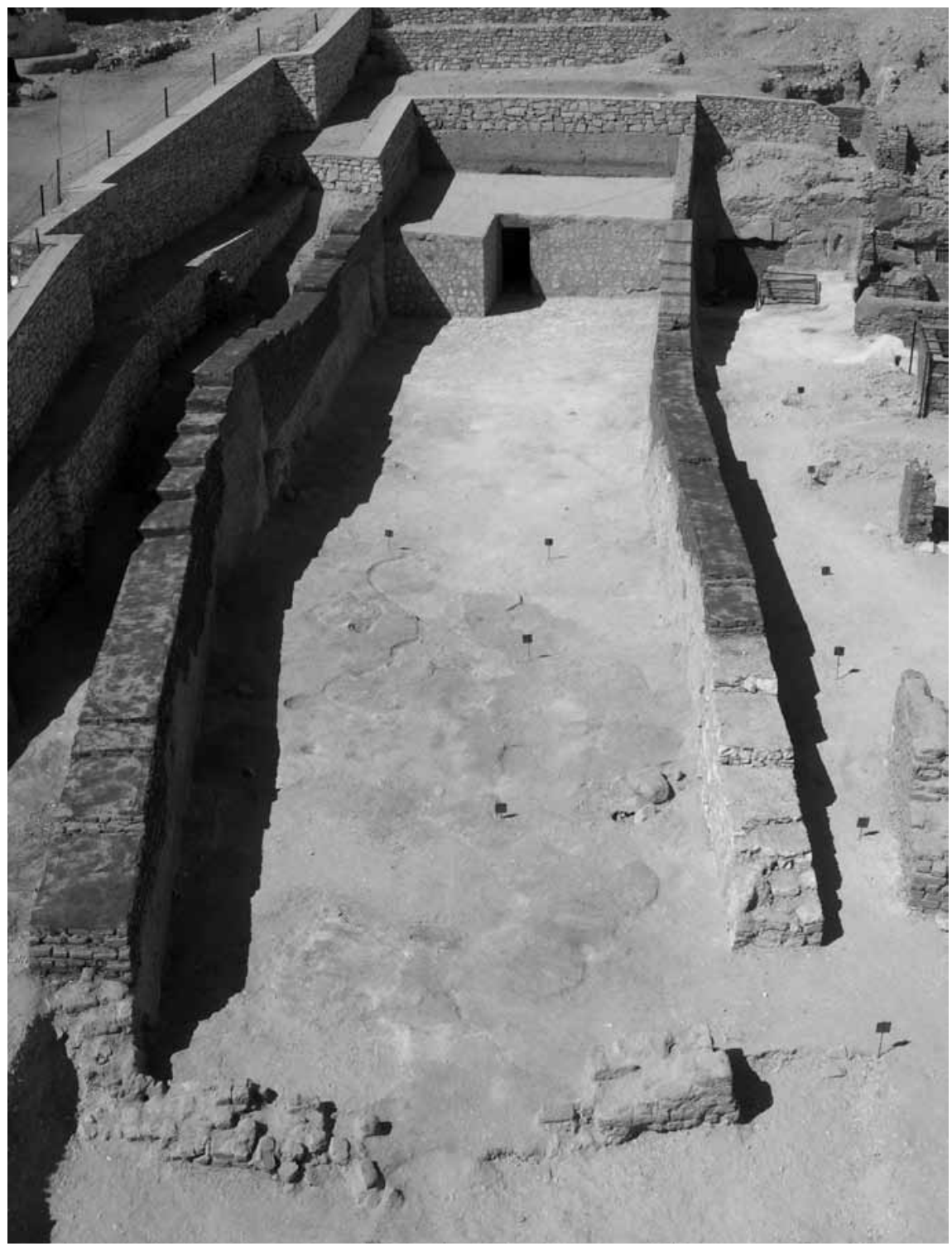

Figura 5. Patio de la tumba de Djehuty (TT 11)

27. Galán y Borrego, 2006. 
por medio de hileras de adobes colocadas sobre la roca. La parte de arriba no parece que terminara en forma redondeada, como sugiere Kampp en su modelo ${ }^{28}$, sino más bien plana. A mayor distancia de la fachada más hileras de adobes eran necesarias, lo que provocó en algún momento que, a unos $12 \mathrm{~m}$. de distancia, gran parte de los adobes de ambos muros se desplomaran sobre el suelo del patio. A partir de los $12 \mathrm{~m}$ los muros laterales se alargan artificialmente.

El muro este se prolonga por medio de mampostería, sobreelevado con hileras de adobes. La anchura del muro es de $0,80 \mathrm{~m}$. La mampostería se construye a base de bloques de piedra caliza bien tallados por la cara que da al interior del patio y unidos por medio de mortero. Sin embargo, la cara que queda por fuera no se construyó desde el suelo, sino que se apoya sobre una pequeña elevación de tierra y lascas de caliza.
El muro oeste, sin embargo, no utiliza mampostería. Sólo ocasionalmente se apoya en alguna piedra de gran tamaño que le sirve de base. En su mayor parte las hileras de adobe se suceden desde el suelo hasta arriba. El grosor es de $1 \mathrm{~m}$. y, a una distancia de $16 \mathrm{~m}$ de la fachada, alcanza una altura de 2,91 m, es decir, que mantiene aproximadamente la altura de la fachada.

Las dimensiones de los adobes empleados en la construcción de ambos muros oscilan entre los siguientes valores: $35 / 39 \mathrm{~cm}$ de longitud, $16 / 18 \mathrm{~cm}$ de anchura y $10 / 12 \mathrm{~cm}$ de altura. Se unen entre sí mediante una capa de mortero blanquecino de unos $2 \mathrm{~cm}$. La cara de los muros que da hacia el patio, tanto la roca, como la mampostería y los adobes, estaba recubierta por una capa de mortero enlucida, que todavía se conserva en varios lugares.

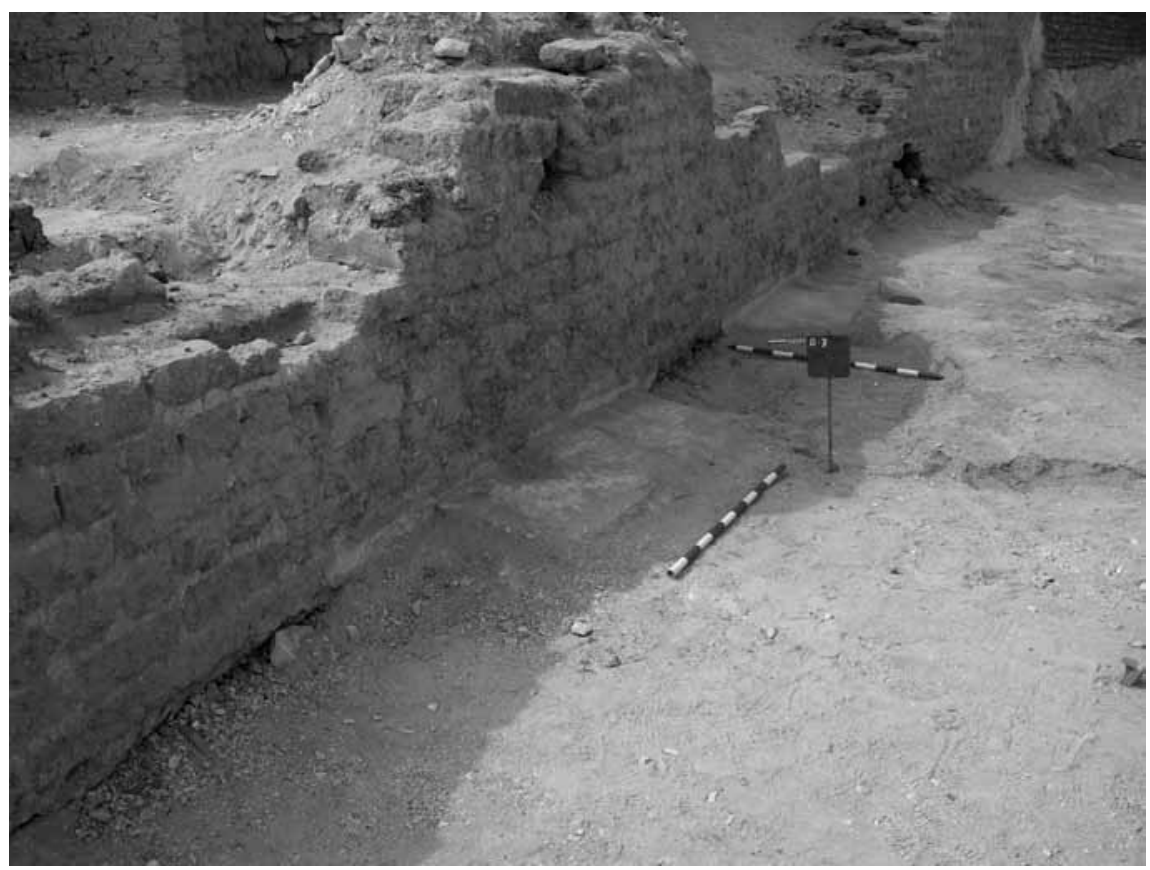

Figura 6. Muro oeste del patio de Djehuty, levantado con adobes, sobre un suelo de relleno (dakka) y con restos de enlucido 


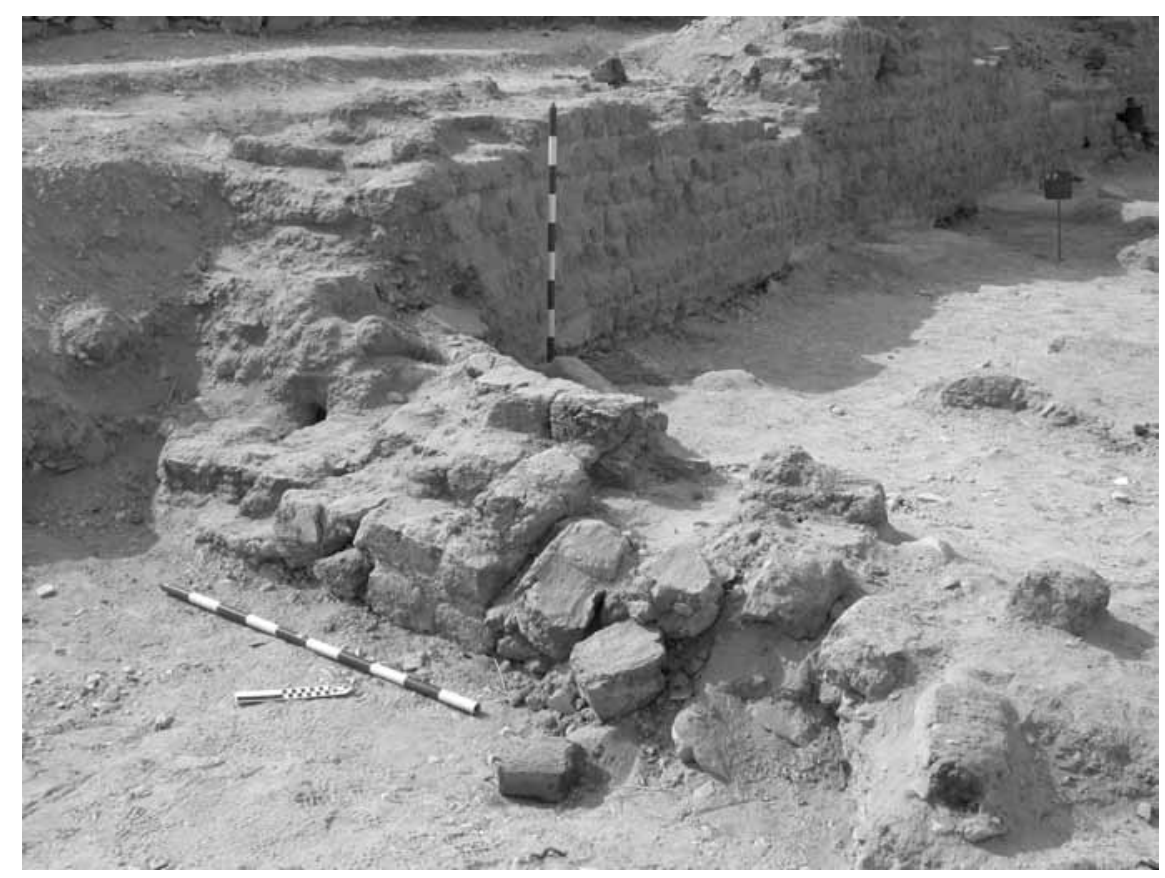

Figura 7. Pilono oeste de la entrada al patio de Djehuty

El suelo del patio está cuidadosamente tallado en la roca hasta una distancia de unos $12 \mathrm{~m}$ de la fachada. A partir de allí la roca desaparece, muy probablemente porque continúa hacia abajo la línea descendente de la colina. El suelo se rellena y nivela entonces con lascas de piedra caliza, que luego se recubren con una capa de tierra endurecida por presión (dakka), que incluso conserva en algunas zonas de los laterales restos del mismo mortero enlucido que se aplicó sobre los muros.

La entrada al patio es ligeramente más estrecha que la fachada; mide $6,30 \mathrm{~m}$. Cada uno de los pequeños "pilonos" mide $1,80 \mathrm{~m}$ de longitud y el vano de la entrada 2,70 m. Los "pilonos" tienen una anchura entre 0,82 y $0,85 \mathrm{~m}$, y conservan una altura máxima de $0,68 \mathrm{~m}$, siendo difícil estimar cuál habría sido su altura original. De todas formas, no parece que fueran demasiado altos, entre otras razones, porque no se ha hallado junto a ellos una cantidad significativa de adobes caídos por el suelo (como pasa en la parte central del patio). Los "pilonos" bajan una hilera de adobes más en la cara exterior que por dentro del patio, lo que parece indicar que habría un pequeño escalón a la entrada, es decir, que el patio de Djehuty estaba algo más elevado que el terreno justo por fuera de la entrada (como ocurre también en el de Baki).

El patio de Djehuty no está perfectamente alineado con la planta de la parte cubierta del monumento funerario, cuyo eje lo compone el pasillo que conduce a la cámara más interna, sino que se desvía ligeramente hacia el este. La desviación se agudiza todavía más hacia la mitad del patio. El muro este aumenta su ángulo hacia el este a unos $16 \mathrm{~m}$ de la fachada, y el muro oeste lo hace a $20 \mathrm{~m}$ de la fachada. Esta desviación en la planta pudiera responder, tal vez, a la presencia de un monumento anterior justo delante de la tumba de Djehuty, a unos treinta metros de su fachada, aunque las 


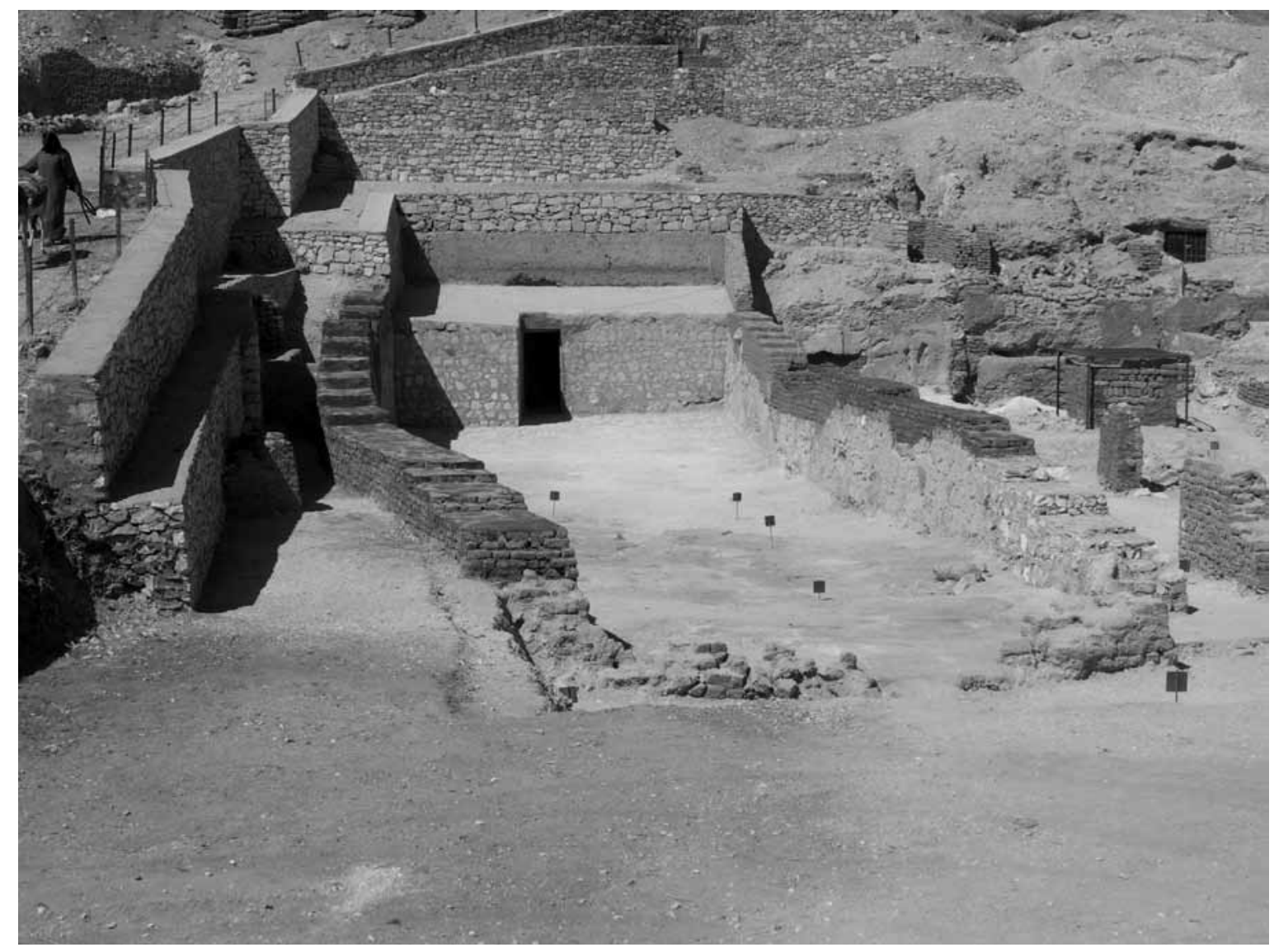

Figura 8. Desviación del eje del patio de Djehuty

verdaderas razones no podrán conocerse hasta que se excave la zona en cuestión.

En este estudio preliminar no se han mencionado los hallazgos en el área dentro de los patios, ni las reutilizaciones de que fueron objeto en épocas posteriores, sin duda aspectos de gran interés arqueológico. Nuestro objetivo en esta ocasión ha sido, en primer lugar, señalar la importancia de los patios de entrada dentro del ritual funerario y, por tanto, dentro de la concepción arquitectónica de los monumentos funerarios. En segundo lugar, incidir sobre lo poco que se conoce de los patios, pues en la mayoría de los casos no han sido todavía excavados, o lo fueron a principios del siglo XX de una forma poco meticulosa $\mathrm{y}$, como consecuencia, su publicación deja muchos detalles sin precisar. Y en tercer lugar, se ha pretendido mostrar cómo, dentro del nuevo enfoque arqueológico que revaloriza el exterior de los monumentos, el Proyecto Djehuty puede ofrecer datos de gran interés $y$, por tanto, contribuir sustancialmente a la comprensión integral de los monumentos funerarios tebanos de época de Hatshepsut y Tutmosis III. 


\section{Bibliografía}

Abdul-Qader Muhammed, M.

1966 The Development of the Funerary Beliefs and Practices Displayed in the Private Tombs of the New Kingdom at Thebes. El Cairo.

Assmann, J.

1987 Die Seit Hatschepsuts und Thutmosis' III. in religionsgeschichtlicher Sicht, en Eggebrecht, A. (ed.): Ägyptens Aufstieg zur Weltmacht, Mainz am Rhein: 47-55.

2001 Tod und Jenseits im Alten Ägypten. Munich.

2003a The Ramesside tomb and the construction of sacred space, en Strudwick, N. y Taylor, J. (eds.): The Theban Necropolis: Past, Present and Future, London: 46-52. $2003 \mathrm{~b}$ The Ramesside tomb of Nebsumenu (TT 183) and the ritual of the Opening of the Mouth, en Strudwick, N. y Taylor, J. (eds.): The Theban Necropolis: Past, Present and Future, London: 53-60.

Bleeker, C. J.

1967 Egyptian Festivals: Enactments of Religious Renewal. Leiden.

Champollion, J. F.

1973 Notices descriptives, 1844-1879 (reimpreso en Genève).

DAvies, N. DE G.

1913 Five Theban Tombs. London.

1922 The Tomb of Puyemrê at Thebes. New York.

1932 Tehuti: Owner of Tomb 110 at Thebes, en Studies presented to F. Ll. Griffith, London: 279-90.

1943 The Tomb of Rekh-mi-Re at Thebes. New York.

Davies, N. de G.; Davies, N. DE G.

1933 The Tombs of Menkheperrasonb, Amenmose, and another. London.
DORMAN, P.

1991 The Tombs of Senenmut. New York.

DziobeK, E.

1987 The Architectural Development of Theban Tombs in the Early Eighteenth Dynasty, en Assmann, J.; Burkard, G. y Davies, V. (eds.): Problems and Priorities in Egyptian Archaeology, London: 69-79.

1994 Die Gräber des Veziers User-Amun. Theben Nr. 61 und 131. Mainz.

ENGELMANN-VON CARNAP, B.

1999 Die Struktur des thebanischen Beamtenfriedhofs in der ersten Hälfte der 18. Dynastie: Analyse von Position, Grundrißgestaltung und Bildprogramm der Gräber. Berlin.

Forman, W.; Quirke, S.

1996 Hieroglyphs and the Afterlife in Ancient Egypt. London.

Galán, J. M.

2004a Investigaciones en las tumbas de Djehuty y de Hery en Dra Abu el-Naga (Luxor): conos funerarios y sarcófagos de madera, en Españoles en el Nilo, I. Misiones arqueológicas en Egipto, Madrid: 147-88.

2004b 'Proyecto Djehuty': Campañas $1^{\mathrm{a}}, 2^{\mathrm{a}}$ y $3^{\mathrm{a}}$ (2002-04), BAEDE 14: 79-99.

$2004 \mathrm{c}$ Conos funerarios hallados en las tres primeras campañas del 'Proyecto Djehuty' (Dra Abu el-Naga, TT 11-12), BAEDE 14: 101-13.

2004d En busca de Djehuty y Hery, National Geographic (edición española): 72-105.

2004e La tabla del aprendiz, National Geographic (edición española): 64-87.

2006 'Proyecto Djehuty': Campañas $4^{\mathrm{a}}$ y $5^{\mathrm{a}}$ (2005-06), BAEDE 16: 47-61.

2007a The Tombs of Djehuty and Hery (TT 11-12) at Dra Abu el-Naga, en Goyon, J.-C. (ed.): IXe Congrès International des Egyptologues, (OLA 150), Leuven: 777-787. 
2007b An Apprentice's Board from Dra Abu el-Naga, JEA 93: 95-116, pl. 2-3.

2007c Tomb chapels of the early XVIIIth Dynasty at Thebes, en Mynarova, J. y Pavel, O. (eds.): Thebes. City of Gods and Pharaohs / Theby. Mesto bohu a faraonu, Praga: 88-101.

2008 Seal impressions from the area of TT 1112 in Dra Abu el-Naga, Memnonia 19: 163-178, pl. 25-31.

2009a Dra Abu el-Naga (Luxor) y el 'Proyecto Djehuty', en M.-C. Pérez Die (ed.), 120 Años de arqueología española en Egipto, Madrid: 78-87, 228-255.

2009 b An intact Eleventh Dynasty burial in Dra Abu el-Naga, EA 35: 32-35.

Galán, J. M.; El-Bialy, M.

2004 An Apprentice's Board from Dra Abu el-Naga, EA 25: 28-40.

Galán, J. M.; Borrego, F.

2006 Funerary Cones from Dra Abu el-Naga (TT 11-12), Memnonia 17: 195-208, pl. 33-39.

Gauthier, M. H.

1908 Sur une campagne de fouilles à Drah Abou'l Neggah en 1906, BIFAO 6: 163-64.

Graefe, E. 1986 s.u. Talfest, L̈̈ VI, Wiesbaden: 187-89.

Guksch, H.

[262] 1978 Das Grab des Benja, gen. Paheqamen. Theben Nr. 343. Mainz.

Hermann, A.

1940 Die Stelen der Thebanischen Felsgräber der 18. Dynastie. Glückstadt.

KAMPP, F.

1996 Die thebanische Nekropole. (Theben 13), Mainz am Rhein.
Kampr-SEYFried, F.

2003 The Theban necrópolis: an overview of topography and tomb development from the Middle Kingdom to the Ramesside period, en Strudwick, N. y Taylor, J. (eds.): The Theban Necrópolis: Past, Present and Future, London: 2-10.

Marquis of Northampton; Spiegelberg, W.;

Newberry, P. E.

1908 Report on some Excavations in the Theban Necropolis during the winter of 1898-9. London.

Mond, R.; EMERy, W. B.

1927 Excavations at Sheikh Abd el Gurneh, 1925-26, Liverpool Annals of Archaeology and Anthropology 14: 28-29.

Naville, E.

1886 Das aegyptische Totenbuch der XVIII. bis $X X$. Dynastie. Berlin.

Petrie, W. M. F.

1909 Qurneh. London.

Polz, D.

1987 Excavation and Recording of a Theban Tomb: Some Remarks on Recording Methods, en Assmann, J.; Burkard, G. y Davies, V. (eds.): Problems and Priorities in Egyptian Archaeology, London: 119-40.

Serrano Delgado, J. M.

2005 Baki, supervisor del ganado de Amón, BAEDE 15: 85-98.

SEYFried, K. J.

1987 Entwicklung in der Grabarchitektur des Neuen Reiches als eine weitere Quelle für teologische Konzeptionen des Ramessidenzeit, en Assmann, J.; Burkard, G. y Davies, V. (eds.): Problems and Priorities in Egyptian Archaeology, London: 219-53. 
Spalinger, A. J.

1996 The Private Feast Lists of Ancient Egypt. (ÄA 57). Wiesbaden.
SPIEGELBERG, W.

1899 Fundjournal- Theben. November $7^{\text {th }} 1898$ - February $9^{\text {th }}$ 1899. Archivo del Griffith Institute, Oxford. 


\section{Trabajos de Egiptología Papers on Ancient Egypt}

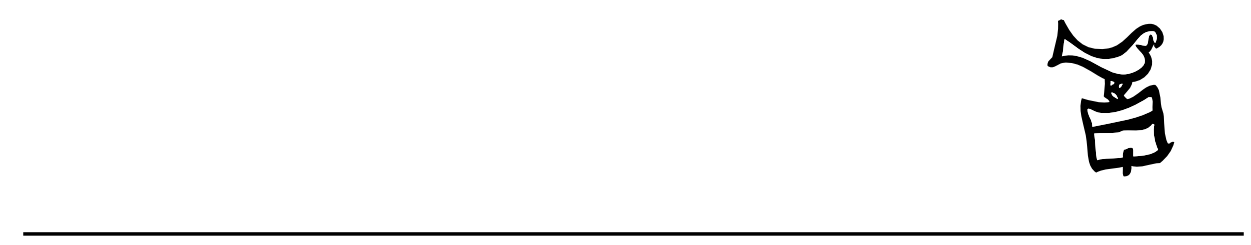

Número 5/1 2009 


\section{Actas \\ III Congreso Ibérico de Egiptología III Congresso Ibérico de Egiptologia}

Editores

Miguel Ángel Molinero Polo Covadonga Sevilla Cueva 


\title{
Editor
}

Miguel Ángel Molinero Polo

Universidad de La Laguna

\section{Consejo Editorial}

\author{
Antonio Pérez Largacha \\ Universidad de Castilla-La Mancha \\ José-R. Pérez-Accino \\ Birkbeck, Universidad de Londres \\ Covadonga Sevilla Cueva \\ Universidad Autónoma de Madrid
}

\section{Comité Científico}

Josep Cervelló i Autuori

Universitat Autònoma de Barcelona

$\mathrm{M}^{\mathrm{a}}$ José lópez Grande

Universidad Autónoma de Madrid

Josep Padró i Parcerisa

Universitat de Barcelona

$\mathrm{M}^{\mathrm{a}}$ Carmen Pérez Die

Museo Arqueológico Nacional, Madrid

Ester Pons Mellado

Museo Arqueológico Nacional, Madrid

José M. Serrano Delgado

Universidad de Sevilla

\section{Colaboradores Editoriales}

Linda Steynor

English editorial assistant

Hervé Mouriacoux

Assistant éditorial pour la langue française 
Trabajos de Egiptología está producida por Isfet. Egiptología e Historia c/ Blanco $1,2^{\circ}$

38400 Puerto de la Cruz

Tenerife-Islas Canarias

España

Maquetación: Proyecto Limón

(C) Autores de los artículos aparecidos

y Consejo Editorial de Trabajos de Egiptología - Papers on ancient Egypt

Depósito Legal: TF-2302-2009

ISSN: $1695-4750$

Imprime: Gráfica Los Majuelos, S.L.L.

imprenta@graficaslosmajuelos.com

Tfno.: 922311455 


\section{Comité Científico \\ III Congreso Ibérico de Egiptología III Congresso Ibérico de Egiptologia}

Miguel Á. Molinero Polo

Universidad de La Laguna

Presidente del Comité Organizador del III Congreso Ibérico de Egiptología

Miembro del Comité Organizador del I Encuentro de Egiptología

Josep Cervelló Autuori

Universitat Autònoma de Barcelona

Presidente del Comité Organizador del II Congreso Ibérico de Egiptologia

José Manuel Galán Allué

Consejo Superior de Investigaciones Cientificas

Director del Proyecto Djehuty, Luxor, Egipto

$\mathrm{M}^{\mathrm{a}}$ Helena Trindade Lopes

Universidad de Lisboa

Directora de la Misión Arqueológica Portuguesa en Menfis

Josep Padró i Parcerisa

Universitat de Barcelona

Director de la Misión Arqueológica de Oxirrinco

Antonio Pérez Largacha

Universidad de Castilla - La Mancha

Miembro del Comité Organizador del I Encuentro de Egiptología

José Ramón Pérez-Accino

Birkbeck College, University of London

Miembro del Comité Organizador del I Encuentro de Egiptología

$\mathrm{M}^{\mathrm{a}}$. Carmen Pérez Díe

Museo Arqueológico Nacional

Directora de la Misión Arqueológica Española en Heracleópolis Magna, Egipto

Covadonga Sevilla Cueva

Universidad Autónoma de Madrid

Miembro del Comité Organizador del I Encuentro de Egiptología 